\title{
The interseismic velocity field of the central Apennines from a dense GPS network
}

\author{
Alessandro Galvani ${ }^{1}{ }^{\star}$, Marco Anzidei $^{1}$, Roberto Devoti ${ }^{1}$, Alessandra Esposito ${ }^{1}$, Grazia Pietrantonio ${ }^{1}$, \\ Anna Rita Pisani ${ }^{1}$, Federica Riguzzi ${ }^{1}$, Enrico Serpelloni ${ }^{2}$
}

\author{
${ }^{1}$ Istituto Nazionale di Geofisica e Vulcanologia, Centro Nazionale Terremoti, Rome, Italy \\ ${ }^{2}$ Istituto Nazionale di Geofisica e Vulcanologia, Centro Nazionale Terremoti, Bologna, Italy
}

\section{Article history}

Received March 2, 2012; accepted July 16, 2012.

Subject classification:

Central Apennines, GPS velocity field, Solutions combination, GPS surveys.

\begin{abstract}
Since 1999, we have repeatedly surveyed the central Apennines through a dense survey-style geodetic network, the Central Apennines Geodetic Network (CAGeoNet). CAGeoNet consists of 123 benchmarks distributed over an area of ca. $180 \mathrm{~km} \times 130 \mathrm{~km}$, from the Tyrrhenian coast to the Adriatic coast, with an average inter-site distance of $3 \mathrm{~km}$ to $5 \mathrm{~km}$. The network is positioned across the main seismogenic structures of the region that are capable of generating destructive earthquakes. Here, we show the horizontal GPS velocity field of both CAGeoNet and continuous GPS stations in this region, as estimated from the position-time series in the time span from 1999 to 2007. We analyzed the data using both the Bernese and GAMIT software, rigorously combining the two solutions to obtain a validated result. Then, we analyzed the strain-rate field, which shows a region of extension along the axis of the Apennine chain, with values from $2 \times 10^{-9} \mathrm{yr}^{-1}$ to $66 \cdot \times 10^{-9} \mathrm{yr}^{-1}$, and a relative minimum of ca. $20 \times 10^{-9} \mathrm{yr}^{-1}$ located in the L'Aquila basin area. Our velocity field represents an improved estimation of the ongoing elastic interseismic deformation of the central Apennines, and in particular relating to the area of the L'Aquila earthquake of April 6, 2009.
\end{abstract}

\section{Introduction}

According to current views, the Apennine chain is an arc-shaped, NE-verging belt that is characterized by a complex pattern of thrusts and folds and normal faults. These are related to two superimposed tectonic phases: an upper Miocene-Lower Pleistocene compressional phase that forms NW-SE-trending thrusts and folds; and the subsequent Quaternary extensional phase that forms NW-SE-trending normal faults. These latter are responsible for the formation of large intramontane basins that have been filled by Plio-Quaternary continental sediments (i.e., the L'Aquila, Rieti, Terni, Fucino and Sulmona basins) [Galadini and Messina 1994, Galadini and Galli 2000] (Figure 1). Some studies have explained the change in the tectonic regime as being caused by the flexural retreat through a roll back mechanism of the lithospheric Adriatic plate that dips below the Apennines [Reutter et al. 1980, Boccaletti et al. 1982, Malinverno and Ryan 1986, Royden et al. 1987, Patacca et al. 1990, Doglioni 1991, Doglioni et al. 1994, Frepoli and Amato 1997, Basili and Barba 2007]. Other studies have ascribed the change in the tectonic regime as being caused by NE motion of the Adriatic microplate relative to Eurasia, around a rotation pole located in northwest Italy [Anderson and Jackson 1987, Calais et al. 2002, D'Agostino et al. 2005, 2008]. At present, the geodetic data show that extensional deformation in the central Apennines is occurring along a narrow belt that is $30 \mathrm{~km}$ to $40 \mathrm{~km}$ wide [Hunstad et al 2003, Serpelloni et al. 2005, Devoti et al. 2008, Devoti et al. 2011], and which is near the areas where the strongest historical (intensity, $\geq \mathrm{XI}$ ) and instrumental earthquakes have occurred [Boschi et al. 1998, Selvaggi 1998] (Figure 1). Starting from 1999, a dense survey-mode GPS network, the Central Apennines Geodetic Network (CAGeoNet), was designed and installed in the central Apennines [Anzidei et al. 2005, 2008]. CAGeoNet consists of 123 benchmarks with an average inter-site distance of $3 \mathrm{~km}$ to $5 \mathrm{~km}$, which are now surrounded by continuously operating GPS stations (Figure 2) and are positioned across the main active faults, as shown by geological and seismological data [Galadini and Galli 2000, Valensise and Pantosti 2001]. The high GPS-station density and the quality of the data collected have provided new insights into the presentday deformation of this seismically active area and information that is useful for seismic hazard assessment.

It has been shown that the combination of independent geodetic solutions obtained with different GPS-processing software [Avallone et al. 2010, Devoti et al. 2012] allows eventual systematic errors to be minimized and final velocity solutions to be validated. In the present study, we have estimated the interseismic strain rates from a combination of independent solutions obtained with the Bernese and GAMIT 


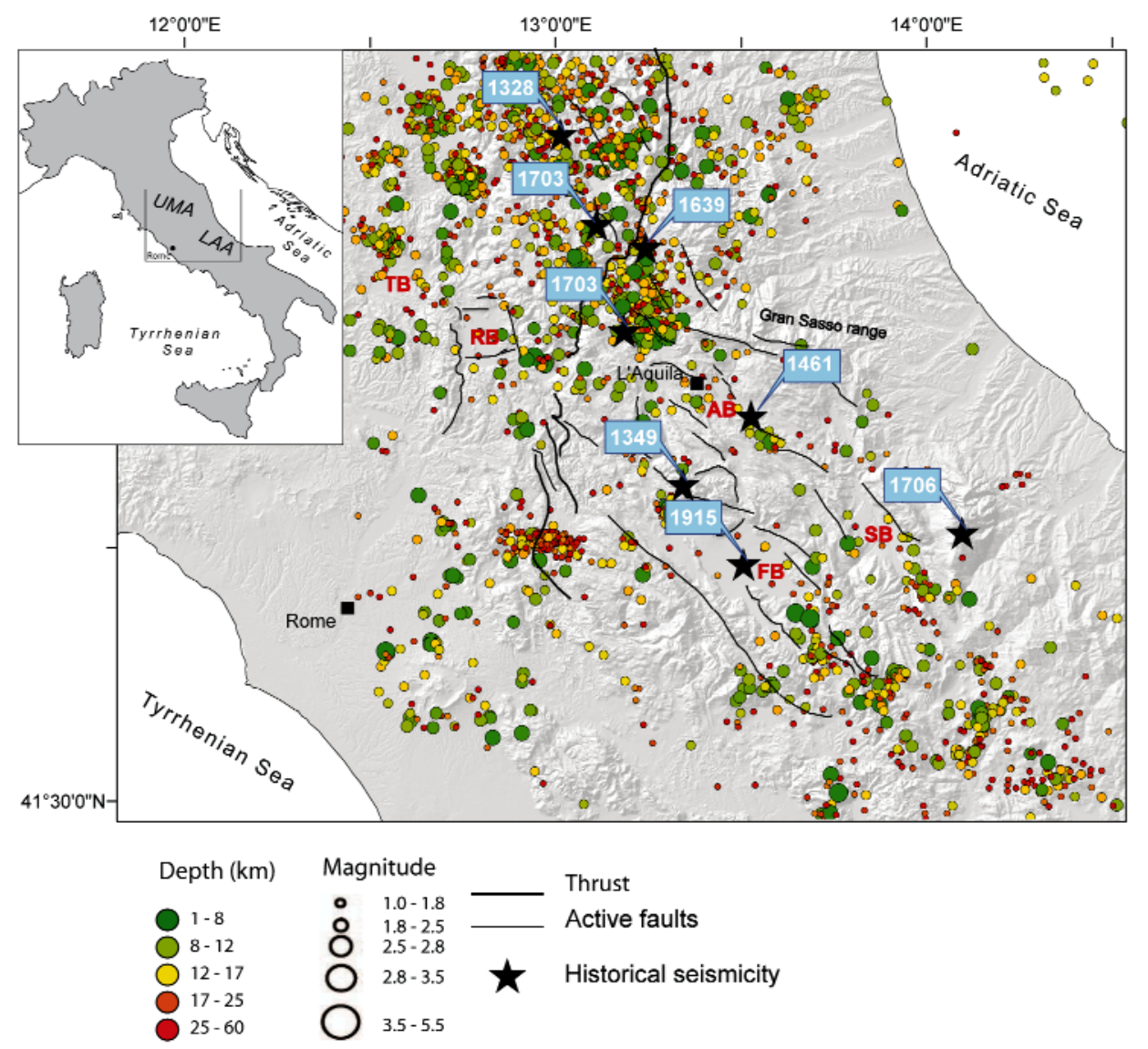

Figure 1. Geological settings of the Umbria-Marche Apennines (UMA) and the Lazio-Abruzzo Apennines (LAA). The main fault systems and intramontane basins are shown (red text): TB, Terni basin; RB, Rieti basin; AB, L'Aquila basin; FB, Fucino basin; SB, Sulmona basin. The instrumental (1978-2008) and historical (I>10) (CPTI04) (http:/ / emidius.mi.ingv.it/CPTI04) seismicity distributions are shown. Inset: Location of the study region within Italy.

software. This has thus allowed us to investigate the geodetic deformation of the interseismic cycle of the Umbria-Marche Apennines (UMA) and the Lazio-Abruzzo Apennines (LAA).

\section{The CAGeoNet and GPS campaigns}

CAGeoNet has provided repeated measurements over the time interval of 1999 to 2007. The surveys were planned taking into account the network grid, the number of stations to be measured simultaneously (up to 11), and the time required to move receivers through the network. Consistent with the logistics, measurements were carried out in approximately the same period of the year, to minimize possible bias due to seasonal variations. Each station was occupied for an average observation window of $48 \mathrm{~h}$, for at least three survey sessions per station, with a sampling rate of $30 \mathrm{~s}$.

Here we discuss the interseismic deformation field that has resulted from the analysis of the velocities obtained from a sub-set of $55 \mathrm{CaGeoNet}$ stations over the time interval of 1999 to 2007.

\subsection{Data processing and combination procedures}

The dataset analyzed (Figure 2) consists of GPS data that were collected on survey-style benchmarks (the CAGeoNet benchmarks) and continuous data that was provided by the continuous GPS networks located in the central Apennines region. The continuous GPS stations belong to different GPS networks: the International Global Navigation Satellite Systems (GNSS) Service (IGS) [http: / / igscb.jpl.nasa.gov]; the Integrated National GPS Network (Rete Integrata Nazionale GPS; RING) [Avallone et al. 2010]; the Italian Space Agency (Agenzia Spaziale Italiana; ASI) [Vespe et al. 2000]; Leica Geosystems (Italian Positioning Service [ItalPos] network); the Region of Abruzzo; and the Universities of Perugia and L'Aquila.

The GPS data cover the period from 1999 to 2007, and they were arranged into several clusters, each of which shared common fiducial continuous GPS stations that were used as anchor stations in the subsequent combinations. Each cluster was independently processed, and then combined through least-squares combination into a single daily solution. The GPS observations were processed using both the Bernese 5.0 [Beutler et al. 2007] and GAMIT 10.34 [Herring et al. 2006] software.

The Bernese processing was based on the Bernese Processing Engine (BPE) procedure that follows standard analysis for regional networks. The daily station coordinates together with the hourly troposphere parameters were solved using the a-priori Dry Niell troposphere model, with the corrections estimated by the Wet Neill mapping function. The ionosphere was neither estimated nor modeled as 
we used the L3 (ionosphere free) linear combination of L1 and L2. The a-priori GPS orbits and the Earth orientation parameters were fixed to the precise IGS products. We applied the ocean-loading Finite Element Solution model FES2004, and used the IGS absolute antenna phase-center corrections. The daily solutions were obtained in a loosely constrained reference frame; i.e., all of the a-priori station coordinates were left free to $10 \mathrm{~m}$ a-priori sigma.

The GAMIT processing followed the standard procedures for the analysis of regional networks [e.g., McClucsky et al. 2000, Serpelloni et al. 2006], with the application of loose constraints to the geodetic parameters. The GAMIT software used double-differenced, ionosphere-free linear combinations of the L1 and L2 phase observations to generate weighted least-square solutions for each daily session [Schaffrin and Bock 1988, Dong and Bock 1989]. An automatic cleaning algorithm [Herring et al. 2006] was applied to post-fit the residuals, to repair cycle slips, and to remove outliers. The observation weights varied with elevation angle and were derived individually for each station from the scatter of the post-fit residuals that was obtained in a preliminary GAMIT solution. The effects of solid-earth tides, polar motion, and oceanic loading were taken into account according to the International Earth Rotation and Reference Systems Service (IERS)/IGS standard 2003 model [McCarthy and Petit 2004]. We applied the FES2004 ocean-loading model and used the IGS absolute antenna phase-center correction table to model the effective receiver and satellite-antenna phase centers. We used orbits provided by the Scrips Orbit Permanent Array Center (SOPAC). The estimated parameters for each daily solution included the three-dimensional



Figure 2. The Central Apennines Geodetic Network (CAGeoNet, triangles) and continuous GPS stations (blue dots) used in the analysis. Inset: Location of the study region within Italy. UMA, Umbria-Marche Apennines; LAA, Lazio-Abruzzo Apennines.

Cartesian coordinates for each station, the six orbital elements for each satellite, the Earth orientation parameters (i.e., pole position and rate, UT1 rate) and the integer phase ambiguities, with the application of loose constraints (ca. $10 \mathrm{~m}$ ) to the a-priori parameters. We also estimated the hourly piecewise linear atmospheric zenith delays at each station, to correct the poorly modeled troposphere, and three east-west and north-south atmospheric gradients per day, to allow for azimuth asymmetry; the associated error covariance matrix was also computed and saved in SINEX format.

Both the analysis procedures (Bernese and GAMIT) produced daily loosely constrained solutions; i.e., free from any a-priori reference frame datum. Coordinates and the com-
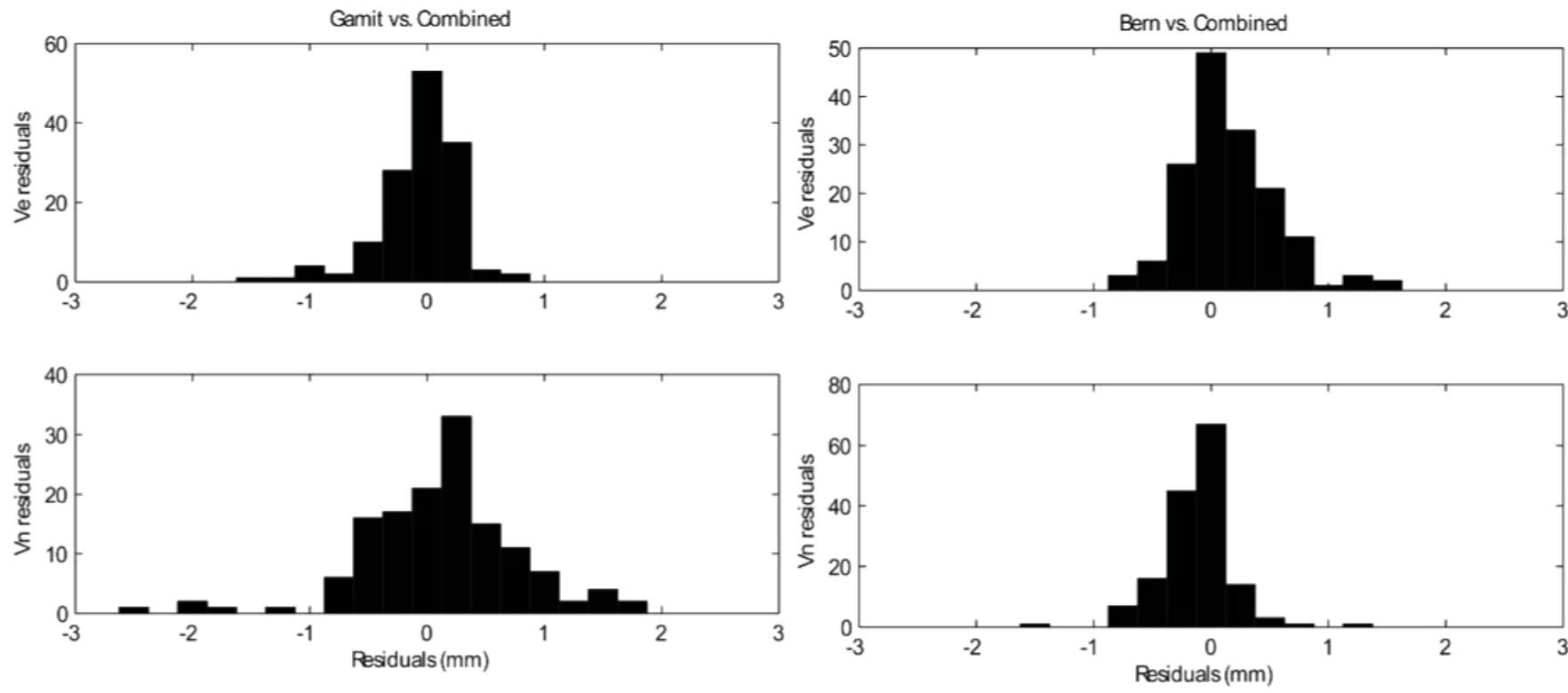

$$
\begin{array}{ll}
\text { Mean Ve }=-0.055 & \text { Std Ve }=0.337(1 \sigma) \\
\text { Mean Vn }=0.135 & \text { Std Vn }=0.661(1 \sigma)
\end{array}
$$

Figure 3. Residuals distributions between the combined and individual Bernese (Bern) and GAMIT (Gamit) solutions. 
plete associated covariance matrices were saved in Solution Independent Exchange (SINEX) format.

The time series of the two solutions were then obtained by applying minimal inner constraints and a four-parameter Helmert transformation, to obtain the coordinates and errors expressed in the IGS05 reference framework (the IGS realization of the ITRF2005 reference framework). Then, we obtained a velocity field for each solution, with the estimation of a linear drift (velocity), annual sinusoid, and occasional offsets due to changes in the station equipment between each time series.

\subsection{Combined GPS velocity field}

The two independent velocity solutions were combined into a unique velocity solution, using a linear least-squares combination approach. The normal matrix was formed from the two independent velocity solutions, and then it was inverted to estimate the unified velocity field of the entire network. As the covariance matrix is usually known separately from a constant multiplier, we also estimated a solution-scale factor together with the combined velocity solution. This ensured that the individual $\chi^{2}$ of each velocity solution was equally balanced (individual solutions do not prevail in the combination process) and the total $\chi^{2}$ is close to unity (realistic errors). The combined solution represents a weighted velocity average that takes into account the correlation ma- trices of the two solutions. The differences between the combined and the individual solutions have low mean values and comparable standard deviations (Figure 3). The values reported in Figure 3 show how the combined solution is placed between the Bernese and GAMIT solutions, and does not give priority to any individual solution. The Bernese solution is slightly more noisy in the east velocity component, while the GAMIT solution is slightly more noisy in the north velocity component. The comparison between the Bernese and GAMIT solutions shows residuals with averages of $-0.2 \mathrm{~mm}$ $\mathrm{yr}^{-1}$ (Ve component) and $0.3 \mathrm{~mm} \mathrm{yr}^{-1}$ (Vn component), and dispersions (at the $1 \sigma$ level) of $0.7 \mathrm{~mm} \mathrm{yr}^{-1}$ and $0.9 \mathrm{~mm} \mathrm{yr}^{-1}$ for Ve and Vn, respectively. The differences are comparable with the averaged sigma values computed for the permanent stations used in the individual solutions $\left(\sigma_{\mathrm{E}}=0.14 \mathrm{~mm} ; \sigma_{\mathrm{N}}=\right.$ $0.23 \mathrm{~mm}$ ), which highlights that the solutions are compatible. We carried out statistical screening between the combined solution with respect to each single solution (Bernese and GAMIT) and the single solutions with respect to each other, both for the permanent and nonpermanent stations, with comparisons of the differences obtained between the average values of Ve and Vn. The stations that showed differences greater than the respective $2 \sigma$ values were discarded.

The combined velocity field with respect to a Eurasianfixed reference frame is shown in Figure 4. The velocity components and their uncertainties are reported in Table 1.

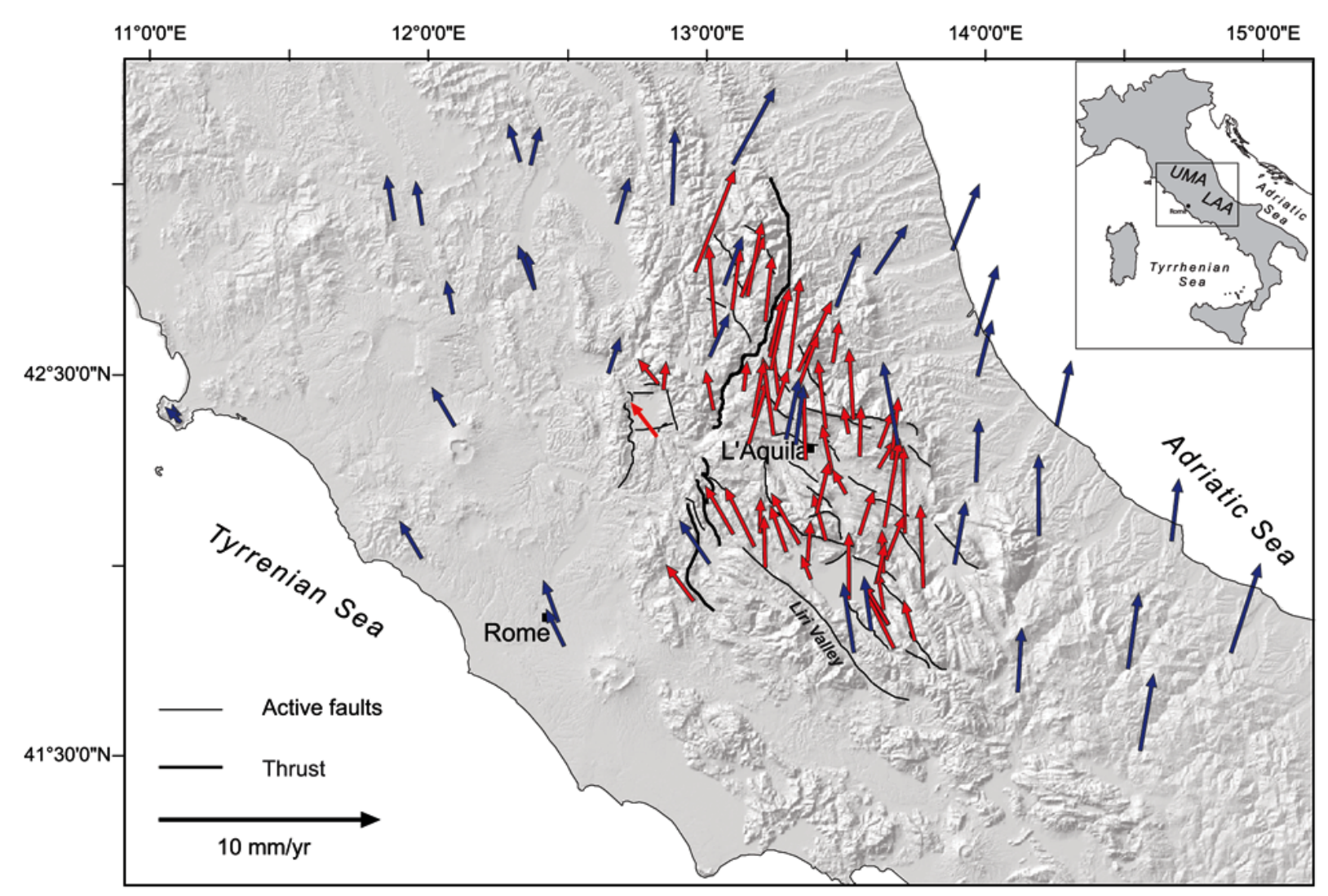

Figure 4. GPS combined velocity fields estimated for the time span from 1999 to 2007 with respect to the Eurasian plate. Red arrows, Central Apennines Geodetic Network GPS velocities; blue arrows, continuous GPS velocities. Inset: Location of the study region within Italy. UMA, Umbria-Marche Apennines; LAA, Lazio-Abruzzo Apennines. 


\begin{tabular}{|c|c|c|c|c|c|c|c|c|c|}
\hline Station & $\begin{array}{c}\text { Latitude } \\
\left({ }^{\circ} \mathbf{N}\right)\end{array}$ & $\begin{array}{c}\text { Longitude } \\
\left({ }^{\circ} \mathrm{E}\right)\end{array}$ & $\begin{array}{c}\text { East } \\
\left(\mathbf{m m ~} \mathbf{~ y r}^{-1}\right)\end{array}$ & $\begin{array}{c}\operatorname{sigE} \\
\left(\mathbf{m m ~ y r}^{-1}\right)\end{array}$ & $\begin{array}{c}\text { North } \\
\left(\mathbf{m m} \mathbf{y r}^{-1}\right)\end{array}$ & $\begin{array}{c}\text { sigN } \\
\left(\mathrm{mm} \mathrm{yr}^{-1}\right)\end{array}$ & $\begin{array}{c}\text { smaj-ax } \\
(\mathrm{mm})\end{array}$ & $\underset{(\mathrm{mm})}{\operatorname{smin}-\mathbf{a x}}$ & Azim \\
\hline ACCU & 42.696 & 13.241 & 0.5 & 1.0 & 3.2 & 1.7 & 2.5 & 1.5 & -173 \\
\hline AQUI & 42.368 & 13.350 & 0.5 & 0.1 & 2.9 & 0.1 & 0.1 & 0.1 & 90 \\
\hline ARAG & 42.411 & 13.459 & -0.2 & 0.6 & 3.3 & 1.1 & 1.7 & 0.9 & -171 \\
\hline ASCO & 42.822 & 13.637 & 1.7 & 0.3 & 2.3 & 0.3 & 0.5 & 0.4 & 176 \\
\hline ATRA & 42.551 & 14.007 & 0.8 & 0.2 & 2.6 & 0.3 & 0.5 & 0.3 & 9 \\
\hline BANO & 42.337 & 13.582 & 0.2 & 1.1 & 2.4 & 1.9 & 3.0 & 1.6 & -171 \\
\hline BLRA & 41.810 & 13.560 & -0.4 & 0.2 & 3.3 & 0.4 & 0.6 & 0.3 & -168 \\
\hline BORB & 42.511 & 13.162 & 0.3 & 1.0 & 1.5 & 1.4 & 2.1 & 1.4 & -179 \\
\hline BSPI & 42.306 & 13.650 & 1.0 & 1.3 & 1.4 & 2.0 & 3.0 & 1.9 & -171 \\
\hline BSSO & 41.546 & 14.594 & 0.8 & 0.1 & 3.6 & 0.2 & 0.3 & 0.2 & -174 \\
\hline CADO & 42.293 & 13.483 & -0.3 & 0.6 & 2.3 & 0.9 & 1.3 & 0.9 & -176 \\
\hline CAME & 43.112 & 13.124 & 2.1 & 0.0 & 3.6 & 0.1 & 0.1 & 0.1 & 179 \\
\hline CASB & 42.390 & 12.849 & -1.1 & 0.9 & 1.7 & 1.5 & 2.3 & 1.4 & 179 \\
\hline CDRA & 42.368 & 13.720 & -0.5 & 0.2 & 3.9 & 0.3 & 0.5 & 0.3 & -170 \\
\hline СЕРP & 42.530 & 12.855 & -0.8 & 0.6 & 1.2 & 0.9 & 1.4 & 0.9 & -169 \\
\hline CERT & 41.949 & 12.982 & -1.1 & 0.2 & 1.8 & 0.2 & 0.4 & 0.2 & -173 \\
\hline CESI & 43.005 & 12.905 & 0.3 & 0.3 & 3.6 & 0.4 & 0.6 & 0.4 & -171 \\
\hline CHNO & 42.654 & 13.062 & -0.2 & 1.3 & 4.4 & 2.0 & 3.1 & 1.9 & -174 \\
\hline CINC & 42.008 & 13.405 & -0.3 & 1.4 & 1.2 & 2.3 & 3.5 & 2.0 & -170 \\
\hline CORT & 42.827 & 12.987 & 2.0 & 1.3 & 4.9 & 2.1 & 3.2 & 2.0 & -173 \\
\hline CPAG & 42.501 & 13.288 & -0.2 & 0.6 & 2.8 & 0.9 & 1.3 & 1.0 & -166 \\
\hline CROG & 42.586 & 13.485 & 0.5 & 0.8 & 2.1 & 1.2 & 1.9 & 1.3 & -177 \\
\hline CTOS & 42.564 & 13.359 & 1.8 & 1.1 & 3.4 & 1.8 & 2.7 & 1.7 & -176 \\
\hline CVAL & 41.984 & 13.811 & 0.0 & 1.4 & 3.9 & 2.4 & 3.7 & 2.0 & -171 \\
\hline CVSE & 42.131 & 13.745 & 0.1 & 1.4 & 4.1 & 2.2 & 3.4 & 2.1 & -173 \\
\hline FCLM & 42.111 & 13.459 & -0.4 & 1.2 & 2.3 & 2.0 & 3.1 & 1.8 & -171 \\
\hline FRCA & 42.059 & 13.678 & 1.0 & 1.3 & 2.2 & 2.1 & 3.2 & 1.9 & -172 \\
\hline FRRA & 42.418 & 14.292 & 0.8 & 0.2 & 3.1 & 0.3 & 0.5 & 0.3 & -172 \\
\hline INGP & 42.383 & 13.316 & 0.8 & 0.1 & 2.9 & 0.2 & 0.3 & 0.2 & -175 \\
\hline INGR & 41.828 & 12.515 & -0.7 & 0.1 & 1.8 & 0.1 & 0.2 & 0.1 & -172 \\
\hline LARI & 41.810 & 14.922 & 1.5 & 0.4 & 4.2 & 0.4 & 0.7 & 0.6 & 172 \\
\hline LNSS & 42.603 & 13.040 & 1.1 & 0.2 & 2.1 & 0.3 & 0.4 & 0.2 & 7 \\
\hline MOSE & 41.893 & 12.493 & -0.5 & 0.2 & 2.0 & 0.3 & 0.4 & 0.3 & 177 \\
\hline MAON & 42.428 & 11.131 & -0.6 & 0.1 & 0.8 & 0.2 & 0.3 & 0.2 & -175 \\
\hline MICI & 42.460 & 13.054 & -0.2 & 0.9 & 2.0 & 1.4 & 2.1 & 1.4 & -171 \\
\hline MLNN & 41.822 & 13.705 & -1.1 & 1.6 & 2.6 & 2.7 & 4.1 & 2.4 & -169 \\
\hline MMAR & 42.102 & 13.363 & -1.2 & 0.7 & 2.5 & 1.2 & 1.9 & 1.0 & -173 \\
\hline MRPN & 41.886 & 13.685 & -1.0 & 1.7 & 2.0 & 2.7 & 4.2 & 2.5 & -173 \\
\hline MRRA & 42.885 & 13.916 & 1.4 & 0.2 & 3.1 & 0.3 & 0.5 & 0.3 & -172 \\
\hline MSAN & 42.761 & 13.154 & 1.3 & 0.9 & 2.9 & 1.2 & 1.9 & 1.3 & -170 \\
\hline MSNI & 42.527 & 13.363 & 1.1 & 1.0 & 2.4 & 1.6 & 2.5 & 1.4 & -173 \\
\hline OCRA & 42.050 & 13.039 & -1.2 & 0.4 & 2.1 & 0.6 & 0.9 & 0.5 & 9 \\
\hline PBRA & 42.124 & 14.229 & 0.1 & 0.2 & 3.8 & 0.3 & 0.5 & 0.3 & -171 \\
\hline PERU & 43.111 & 12.394 & 0.6 & 0.4 & 1.9 & 0.5 & 0.8 & 0.6 & 165 \\
\hline PESC & 42.024 & 13.667 & 0.1 & 1.1 & 2.1 & 1.7 & 2.6 & 1.6 & -170 \\
\hline POCA & 42.571 & 13.326 & 0.7 & 0.9 & 4.3 & 1.2 & 1.8 & 1.3 & -177 \\
\hline POGB & 42.515 & 12.873 & 0.3 & 0.8 & 1.4 & 1.3 & 2.1 & 1.2 & 9 \\
\hline PPEZ & 42.183 & 13.426 & 0.7 & 1.2 & 2.5 & 2.0 & 3.1 & 1.7 & -175 \\
\hline
\end{tabular}

Table 1 (continues on following page). 
GALVANI ET AL.

\begin{tabular}{|c|c|c|c|c|c|c|c|c|c|}
\hline Station & $\begin{array}{c}\text { Latitude } \\
\left({ }^{\circ} \mathbf{N}\right)\end{array}$ & $\begin{array}{c}\text { Longitude } \\
\left({ }^{\circ} \mathrm{E}\right)\end{array}$ & $\begin{array}{c}\text { East } \\
\left(\mathbf{m m ~} \mathbf{~ y r}^{-1}\right)\end{array}$ & $\begin{array}{c}\operatorname{sigE} \\
\left(\mathbf{m m ~ y r}^{-1}\right)\end{array}$ & $\begin{array}{c}\text { North } \\
\left(\mathbf{m m} \mathbf{y r}^{-1}\right)\end{array}$ & $\begin{array}{c}\text { sigN } \\
\left(\mathrm{mm} \mathrm{yr}^{-1}\right)\end{array}$ & $\begin{array}{c}\text { smaj-ax } \\
(\mathrm{mm})\end{array}$ & 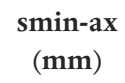 & Azim \\
\hline PSCA & 42.128 & 13.125 & -1.2 & 1.1 & 2.3 & 1.8 & 2.7 & 1.7 & -174 \\
\hline PSMA & 42.127 & 13.581 & 0.8 & 1.1 & 2.1 & 1.7 & 2.6 & 1.7 & -175 \\
\hline PSTE & 42.428 & 11.120 & -0.1 & 0.7 & 1.0 & 0.8 & 1.2 & 1.1 & 164 \\
\hline REFO & 42.956 & 12.704 & 0.8 & 0.1 & 2.2 & 0.2 & 0.2 & 0.2 & -173 \\
\hline RENO & 42.793 & 13.093 & 1.0 & 0.1 & 2.3 & 0.1 & 0.2 & 0.1 & -171 \\
\hline REPI & 42.952 & 12.002 & -0.1 & 0.1 & 2.1 & 0.2 & 0.2 & 0.1 & -173 \\
\hline RETO & 42.782 & 12.407 & -0.2 & 0.1 & 1.8 & 0.1 & 0.2 & 0.1 & -173 \\
\hline RIET & 42.408 & 12.857 & 0.1 & 0.5 & 0.0 & 0.6 & 1.0 & 0.8 & 177 \\
\hline RIFP & 42.763 & 13.176 & 0.9 & 0.9 & 3.6 & 1.4 & 2.1 & 1.4 & -174 \\
\hline RNI2 & 41.703 & 14.152 & 0.3 & 0.1 & 3.1 & 0.2 & 0.4 & 0.2 & 7 \\
\hline ROCA & 42.328 & 13.697 & 0.5 & 1.0 & 3.0 & 1.6 & 2.5 & 1.5 & -173 \\
\hline ROFA & 42.397 & 13.541 & -0.1 & 0.7 & 1.3 & 1.1 & 1.6 & 1.0 & -174 \\
\hline ROIO & 42.327 & 13.386 & 0.1 & 0.4 & 3.6 & 0.5 & 0.8 & 0.6 & 176 \\
\hline RSTO & 42.658 & 14.001 & 1.2 & 0.0 & 3.3 & 0.1 & 0.1 & 0.1 & -177 \\
\hline S260 & 42.601 & 13.257 & 0.8 & 1.2 & 2.8 & 1.8 & 2.8 & 1.8 & -170 \\
\hline SCIN & 42.434 & 13.559 & 0.0 & 0.6 & 3.4 & 1.1 & 1.7 & 0.9 & -171 \\
\hline SCRA & 42.268 & 14.002 & 0.3 & 0.2 & 3.0 & 0.3 & 0.4 & 0.3 & -171 \\
\hline SECI & 42.148 & 13.670 & 0.9 & 1.2 & 4.2 & 1.8 & 2.8 & 1.8 & -174 \\
\hline SELL & 42.369 & 13.180 & 1.1 & 0.7 & 3.1 & 0.9 & 1.3 & 1.0 & 176 \\
\hline SI01 & 42.964 & 11.901 & -0.2 & 0.6 & 2.2 & 0.7 & 1.1 & 0.9 & 173 \\
\hline SIER & 41.925 & 13.668 & -0.1 & 1.1 & 1.9 & 1.9 & 2.8 & 1.7 & -173 \\
\hline SLLI & 42.727 & 13.121 & 0.6 & 1.6 & 3.0 & 2.4 & 3.6 & 2.3 & -174 \\
\hline SLUC & 42.567 & 13.261 & 1.0 & 1.5 & 3.9 & 2.1 & 3.3 & 2.2 & 5 \\
\hline SMCO & 42.393 & 13.271 & -0.3 & 0.6 & 3.7 & 0.9 & 1.4 & 0.9 & -179 \\
\hline SMPQ & 42.055 & 13.394 & 0.3 & 0.8 & 2.0 & 1.4 & 2.1 & 1.2 & -173 \\
\hline SMRA & 42.048 & 13.924 & 0.7 & 0.2 & 3.0 & 0.3 & 0.4 & 0.3 & -170 \\
\hline SORB & 42.082 & 13.317 & -0.6 & 1.2 & 2.2 & 1.9 & 2.9 & 1.8 & -174 \\
\hline SS83 & 41.842 & 13.780 & -0.4 & 1.7 & 2.0 & 2.8 & 4.2 & 2.5 & -173 \\
\hline SSMF & 42.131 & 13.221 & 0.2 & 1.0 & 1.7 & 1.6 & 2.5 & 1.6 & -177 \\
\hline SSTS & 42.360 & 13.651 & 0.8 & 1.1 & 1.8 & 2.1 & 3.1 & 1.7 & -172 \\
\hline TARI & 42.459 & 13.276 & 0.8 & 1.2 & 2.0 & 1.9 & 2.9 & 1.8 & -170 \\
\hline TNER & 42.237 & 13.532 & -0.5 & 1.1 & 1.2 & 2.0 & 3.0 & 1.7 & -173 \\
\hline TODI & 42.781 & 12.408 & -0.6 & 0.6 & 2.2 & 0.7 & 1.1 & 0.9 & 155 \\
\hline TOLF & 42.064 & 12.000 & -0.9 & 0.1 & 1.8 & 0.2 & 0.3 & 0.2 & -174 \\
\hline TRAS & 41.954 & 13.543 & 0.1 & 1.1 & 3.2 & 1.6 & 2.5 & 1.6 & 11 \\
\hline TRIV & 41.767 & 14.550 & 0.7 & 0.2 & 3.6 & 0.3 & 0.5 & 0.3 & -171 \\
\hline TRMT & 42.096 & 13.201 & -1.2 & 0.7 & 2.8 & 1.2 & 1.9 & 1.0 & -172 \\
\hline TRNE & 42.441 & 13.198 & 0.7 & 0.8 & 2.7 & 1.3 & 2.0 & 1.2 & -173 \\
\hline UNOV & 42.716 & 12.113 & -0.1 & 0.2 & 1.7 & 0.3 & 0.5 & 0.3 & -172 \\
\hline UNPG & 43.119 & 12.356 & -0.4 & 0.1 & 1.9 & 0.2 & 0.2 & 0.2 & 179 \\
\hline UNTR & 42.559 & 12.674 & 0.7 & 0.1 & 1.7 & 0.2 & 0.2 & 0.2 & 179 \\
\hline VCRA & 42.735 & 13.498 & 1.3 & 0.2 & 3.0 & 0.4 & 0.6 & 0.3 & -174 \\
\hline VITE & 42.418 & 12.119 & -0.9 & 0.7 & 1.9 & 0.8 & 1.2 & 1.0 & 177 \\
\hline VNRE & 42.001 & 13.646 & 0.5 & 0.9 & 1.9 & 1.6 & 2.4 & 1.4 & -173 \\
\hline VRCE & 42.039 & 13.240 & 0.1 & 0.8 & 2.5 & 1.3 & 2.0 & 1.1 & -174 \\
\hline VTRA & 42.110 & 14.708 & 0.5 & 0.2 & 2.9 & 0.3 & 0.4 & 0.3 & -171 \\
\hline VVLO & 41.870 & 13.623 & -0.2 & 0.1 & 2.6 & 0.2 & 0.3 & 0.2 & -174 \\
\hline
\end{tabular}

Table1 (continues from previous page). Velocity field dataset of the CAGeoNet and of the surrounding continuous GPS stations used in the analysis. East, North, velocities; sigE, sigma E; sigN, sigma N; smaj-ax, smin-ax, error ellipses; Azim, azimuth. 

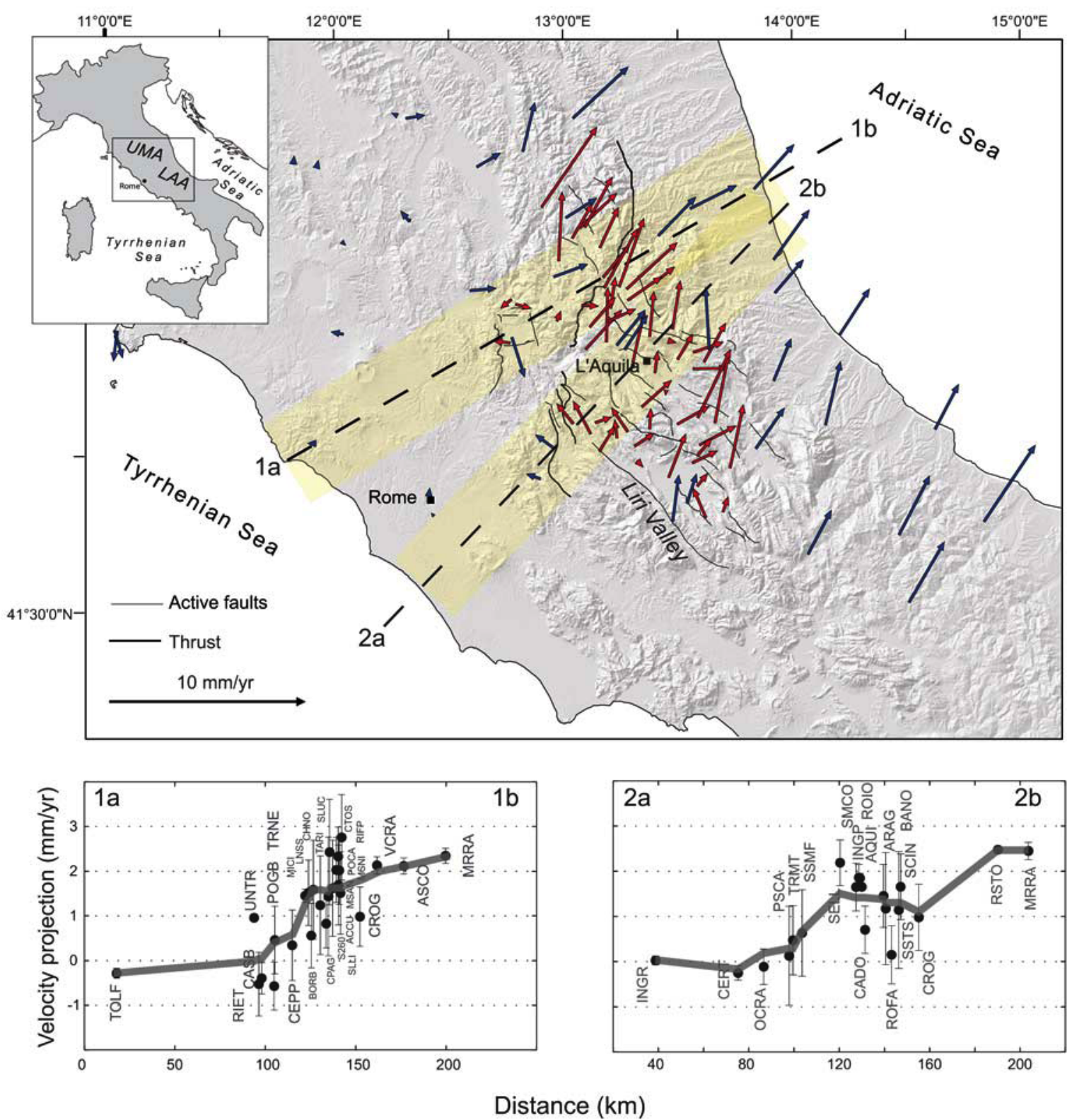

Figure 5. Velocity projections along the transect directions $1 \mathrm{a}-1 \mathrm{~b}$ and $2 \mathrm{a}-2 \mathrm{~b}$. The projections involved vertices at distances of $20 \mathrm{~km}$ and $15 \mathrm{~km}$ in both perpendicular directions along the transect directions for the profiles $1 \mathrm{a}-1 \mathrm{~b}$ and $2 \mathrm{a}-2 \mathrm{~b}$, respectively. Inset: Location of the study region within Italy. UMA, Umbria-Marche Apennines; LAA, Lazio-Abruzzo Apennines.

The Eurasia plate was fixed, minimizing the horizontal velocities of 24 stations located on the stable part of the plate. The selection of Eurasian stations was statistically inferred using a $\chi^{2}$ test-statistic to select the subset of stations that defined the stable plate [Noquet et al. 2001], starting from the triad of the WSTR, WTZR and ZIMM stations in ITRF2005. The estimated Euler pole and rotation rate for the Eurasia plate were at $55.85^{\circ} \mathrm{N}, 95.72^{\circ} \mathrm{W}$ and $0.266^{\circ} \pm 0.003^{\circ} \mathrm{Myr}^{-1}$ respectively.

The geodetic strain rate was evaluated by a distanceweighted approach, and computed using all of the stations on a regularly spaced grid, applying the weighting algorithm developed by Shen et al. [1996]. The contribution of each station velocity to the strain-rate computed on a given node was down-weighted with the function $\mathrm{W}=\exp \left(-d^{2} / \alpha^{2}\right)$, where $d$ is the distance between each node and the stations, and $\alpha$ is the smoothing distance parameter. The algorithm selects the optimal $\alpha$ value from a given a-priori interval, which depends on the spatial distribution of the GPS sites; consequently, strain-rate maps were obtained with spatially variable $\alpha$.

The second invariant rate was obtained by interpolation of the velocity horizontal components on a $0.1^{\circ} \times 0.1^{\circ}$ regular grid. The smoothing factor down-weights the velocities in the range from $20 \mathrm{~km}$ to $100 \mathrm{~km}$, according to the network density (Figure 6).

\section{Results}

The combined horizontal velocity field expressed with respect to a fixed Eurasian plate showed: (i) good coherence between the velocities estimated from the CAGeoNet (Figure 4, red arrows) and CGPS (Figure 4, blue arrows) stations; 




Figure 6. The second invariant estimated on a $0.1^{\circ} \times 0.1^{\circ}$ regular grid, according to the algorithm of Shen et al. [1996]. AAL, Ancona Anzio Line; UMA, Umbria-Marche Apennines; LAA, Lazio-Abruzzo Apennines. Inset: Location of the study region within Italy.

and (ii) two different and characteristic main velocity patterns: a NNW-oriented trend in the Tyrrhenian Apennine sector, and a NNE-oriented trend in the Adriatic Apennine sector. A gradual clockwise velocity rotation was clearly evident from $\mathrm{W}$ to $\mathrm{E}$, where the velocities were initially NNWoriented and rotated towards the NNE with increasing values (0.9-5.2 $\left.\mathrm{mm} \mathrm{yr}^{-1}\right)$. This pattern showed an anomaly in the L'Aquila basin, where the vectors were turned in an ca. NS directed, as normal to the main tectonic structures of the Gran Sasso range (Figure 4).

To show the velocity gradients better across the central Apennine chain, we represented the velocity field with respect to a fixed Tyrrhenian coast (Figure 5), and then projected the velocities along two profiles crossing the studied area: ENE-WSW-oriented. The two profiles are parallel to the average direction of the velocity vectors and approximately normal to the main fault systems. Profile (1) was located across the UMA, while profile (2) was located across the LAA sector. The projections contained all of the velocities within the distance of $40 \mathrm{~km}$ (profile 1), and $30 \mathrm{~km}$ (profile 2). To highlight the velocity gradient, we used a moving-average filter with a 40-km window (Figure 5, gray line). The net extension rates across the two cross-sections were the same, at ca. $2.5 \mathrm{~mm} \mathrm{yr}^{-1}$, but they spread over different distances. Profile (1) showed a velocity variation that was concentrated in a narrow strip of ca. $60 \mathrm{~km}$, with a maximum step of $1.5 \mathrm{~mm} \mathrm{yr}^{-1}$ at about $30 \mathrm{~km}$, on the western flank of the chain with a strain rate of ca. $50 \cdot \times 10^{-9} \mathrm{yr}^{-1}$. Profile (2) showed a more irregular velocity variation, with a negative (i.e., shortening component) gradient that roughly corresponded with the L'Aquila basin (between $120 \mathrm{~km}$ and
$150 \mathrm{~km}$; Figure 5, profile 2), and developed along larger distances (ca. $100 \mathrm{~km}$.) with respect to profile (1), with a lower strain rate of ca. $20 \cdot \times 10^{-9} \mathrm{yr}^{-1}$. The predominantly extensional deformation was mainly oriented NE-SW, and ranged from $2 \pm 11 \cdot \times 10^{-9} \mathrm{yr}^{-1}$ to $66 \pm 19 \cdot \times 10^{-9} \mathrm{yr}^{-1}$ (Figure 6).

For the UMA, the extensional deformation was distributed over a relatively wide area, and coincided with the culmination of the topographic relief. The distribution of the extension area became narrower and shifted towards the SW, crossing the Ancona-Anzio Line, and had slightly lower extension rates.

These estimations are in general agreement with those obtained by previous geodetic and geologic data for this area. From the geologic data, which included both interseismic and coseismic deformation, Galadini and Galli [2000] obtained an extension rate from $0.7 \mathrm{~mm} \mathrm{yr}^{-1}$ to $1.6 \mathrm{~mm} \mathrm{yr}^{-1}$ across the main active fault sets recognized in the area. Using fault-slip vectors, Faure Walker et al. [2010] calculated strain rates averaged over $15 \mathrm{kyr}$ of $12 \cdot \times 10^{-9} \mathrm{yr}^{-1}$ and an extension rate of $1 \mathrm{~mm} \mathrm{yr}^{-1}$ over a $160 \mathrm{~km} \times 80 \mathrm{~km}^{-1}$ area, which was consistent with a strain rate $\leq 38 \cdot \times 10^{-9} \mathrm{yr}^{-1}$ estimated in $5 \mathrm{~km} \times 80 \mathrm{~km}$ boxes that crossed the strike of the central Apennines. From geodetic data, Serpelloni et al. [2005] indicated $31 \cdot \times 10^{-9} \mathrm{yr}^{-1}$, while D'Agostino et al. [2008] showed a second invariant band parallel to the chain with values $>50 \cdot \times 10^{-9} \mathrm{yr}^{-1}$. Devoti et al. $[2008,2011]$ estimated an extension rate of $50 \cdot \times 10^{-9} \mathrm{yr}^{-1}$. Our results do not agree with those obtained by Pesci et al. [2010] on a CAGeoNet network sub-set. They found NE shortening corresponding to the UMA, NW shortening in the Liri Valley, and a wide area that was characterized by NE extension in the eastern portion of the LAA. 
A relative minimum of the second invariant of the strain $\left(20 \cdot \pm 11 \times 10^{-9} \mathrm{yr}^{-1}\right)$ was seen in the area where the April 6, 2009 , earthquake occurred (Figure 6). This value is congruent with the extension rate of $10 \pm 4 \cdot \times 10^{-9} \mathrm{yr}^{-1}$ that was obtained by Doglioni et al. [2011] using only continuous GPS stations. The L'Aquila basin area, which has experienced large historical earthquakes in the past, was characterized by a relative low instrumental seismicity over the last 30 years (1978-2008) (Figure 1).

Viscoelastic earthquake cycle models [e.g., Lundgren et al. 2009] have shown that velocity gradients across faults can depend on crustal rheology and on the fault stage in the earthquake cycle. The relatively low strain rate observed across the L'Aquila basin by the dense CaGeoNet network can be interpreted in this light as being due to its position in a later stage of the earthquake cycle [e.g., Doglioni et al. 2011].

\section{Conclusions}

We processed more than 100 GPS stations in central Italy as a combination of both permanent and survey-style networks. Due to the high number of stations and their short inter-distances $(3-5 \mathrm{~km})$, our dataset has provided the most detailed view of the sub-regional deformation field of this area. To validate our results, we used two different strategies and GPS data-processing software. The two independent velocity solutions strongly agree (horizontal weighted root mean square, $1.1 \mathrm{~mm} \mathrm{yr}^{-1}$ ), and their combination represents the best compromise of the available solution. As relevant seismicity did not occur in the LAA during the time span considered (Figure 1), we can assume that the velocity field observed is purely interseismic, and thus it describes the regional and elastic deformation field before the 2008-2009 L'Aquila seismic sequence that culminated in the April 6, 2009, $M_{W} 6$ earthquake. The horizontal velocities of our nonpermanent stations often showed large uncertainties (average values ca. 1.0 and $1.5 \mathrm{~mm} \mathrm{yr}^{-1}$ for Ve and $\mathrm{Vn}$, respectively); nevertheless, they are consistent with the continuous GPS velocity-field estimated in this area. The horizontal velocities and the strain-rate results are consistent with the major tectonic features of the central Apennines, showing a NE-SW extensional deformation style.

We estimated a differential velocity of about $2.5 \mathrm{~mm} \mathrm{yr}^{-1}$ across the Apennines, with the recognition of two different extensional deformation patterns: the UMA sector showed a gradual velocity increase from $\mathrm{W}$ to $\mathrm{E}$; while the LAA sector showed an irregular velocity increase that was characterized by two small steps. A moderate velocity decrease was located in correspondence with the L'Aquila basin. The total strainrate values ranged from $2 \times 10^{-9} \mathrm{yr}^{-1}$ to $66 \times 10^{-9} \mathrm{yr}^{-1}$. A relative minimum of about $20 \times 10^{-9} \mathrm{yr}^{-1}$ was located in the area of the L'Aquila basin, thus emphasizing the possible role of strain-rate patterns in seismic hazard assessment. Shen et al. [2007] observed that regions with higher strain concen- trations are more prone to be the source of future earthquakes, and thus the relative minimum observed in the L'Aquila basin should not necessarily represent a decrease in the probability of earthquake occurrence, but might be interpreted as due to the locked part of the fault in the brittle upper crust that approaches the end of the seismic cycle [Lundgren et al. 2009, Doglioni et al. 2011].

Despite the high concentration of the stations in the L'Aquila area, more near-field studies are necessary to solve the behavior of the crust in this region, which thus keeps the debate open.

Acknowledgements. The authors would like to thank Angelo Massucci and Sergio Del Mese for the CAGeoNet field work and data storage.

\section{References}

Anderson, H., and J. Jackson (1987). Active tectonics of the Adriatic region, Geophys. J. Roy. Astron. Soc., 91, 937-983. Anzidei, M., P. Baldi, A. Pesci, A. Esposito, A. Galvani, F. Loddo, P. Cristofoletti, A. Massucci and S. Del Mese (2005). Geodetic deformation across the central Apennines from GPS data in the time span 1999-2003, Annals of Geophysics, 48 (2), 259-271.

Anzidei, M., P. Baldi and E. Serpelloni (2008). The coseismic ground deformations of the 1997 Umbria-Marche earthquakes: a lesson for the development of new GPS networks, Annals of Geophysics, 51 (2/3), 27-43.

Avallone, A., G. Selvaggi, E. D'Anastasio, N. D'Agostino, G. Pietrantonio, F.Riguzzi, E. Serpelloni, M. Anzidei, G. Casula, G. Cecere, C. D'Ambrosio, P. De Martino, R. Devoti, L. Falco, M. Mattia, M. Rossi, F. Obrizzo, U. Tammaro and L. Zarrilli (2010). The RING network: improvements to a GPS velocity field in the central Mediterranean, Annals of Geophysics, 53 (2), 39-54; doi:10.4401/ag-4549.

Basili, R., and S. Barba (2007). Migration and shortening rates in the northern Apennines, Italy: implications for seismic hazard, Terra Nova, 19, 462-468; doi:10.1111/J.13653121.2007.00772.x 2007.

Beutler, G., et al. (2007). Bernese GPS Software, In: R. Dach, U. Hugentobler, P. Fridez and M. Meindl (eds.), Astronomical Institute, University of Bern, Bern (January 2007).

Boccaletti, M., C. Conedera, P. Dainelli and P. Gocev (1982). The recent (Miocene-Quaternary) regmatic system of the western Mediterranean region, J. Pet. Geol., 5, 31-49.

Boschi, E., E. Guidoboni, G. Ferrari and G. Valensise (1998). I terremoti dell'Appenino Umbro-Marchigiano (area sud orientale dal 99 a. C. al 1984), ING-SGA, Bologna, Italy (in Italian).

Calais, E., J.M. Noquet, F. Jouanne and M. Tardy (2002). Current strain regime in the western Alps from continuous global positioning system measurements, 1996-2001, Geology, 7, 651-654.

D'Agostino, N., D. Cheloni, S. Mantenuto, G. Selvaggi, A. 
Michelini and D. Zuliani (2005). Strain accumulation in the southern Alps (NE Italy) and deformation at the northeastern boundary of Adria observed by CGPS measurements, Geophys. Res. Lett., 32, L19306; doi:10.1029/ 2005GL024266.

D'Agostino, N.A. Avallone, D. Cheloni, E. D'Anastasio, S. Mantenuto and G. Selvaggi (2008). Active tectonics of the Adriatic region from GPS and earthquake slip vectors, J. Geophys. Res., 113, B12413; doi:10.1029/2008JB005860.

Devoti, R., F. Riguzzi, M. Cuffaro and C. Doglioni (2008). New GPS constraints on the kinematics of the Apennines subduction, Earth Planet Sci. Lett., 273, 163-174.

Devoti, R., A. Esposito, G. Pietrantonio, A.R. Pisani and F. Riguzzi (2011). Evidence of large-scale deformation patterns from GPS data in the Italian subduction boundary, Earth Planet Sci. Lett., 311, 230-241; doi:10.1016/J.epsl. 2011.09.034.

Devoti, R., E. Flammini, G. Pietrantonio, F. Riguzzi and E. Serpelloni (2012). Toward a dense Italian GPS velocity field: data analysis strategies and quality assessment, In: N. Sneeuw et al. (eds.), VII Hotine-Marussi Symposium on Mathematical Geodesy, International Association of Geodesy Symposia vol. 137, Berlin/Heidelberg, SpringerVerlag, pp. 34-346; doi:10.1007/978-3-642-22078-4.

Doglioni, C. (1991). A proposal for kinematic modeling of W-dipping subduction-possible applications to the Tyrrhenian-Apennines system, Terra Nova, 3, 423-434.

Doglioni, C., F. Mongelli and P. Pieri (1994). The Puglia uplift (SE Italy): an anomaly in the foreland of the Apenninic subduction due to buckling of a thick continental lithosphere, Tectonics, 13, 1309-1321.

Doglioni, C., S. Barba, E. Carminati and F. Riguzzi (2011). Role of the brittle-ductile transition on fault activation, Phys. Earth Planet. Inter., 184, 160-171; doi:10.1016/j.pepi. 2010.11.005.

Dong, D., and R.W. Bock (1989). GPS network analysis with phase ambiguity resolution applied to crustal deformation studies in California, J. Geophys. Res., 94, 3949-3966.

Faure Walker, J.P., G.P. Roberts, P.R. Sammonds and P. Cowie (2010). Comparison of earthquake strains over $10^{2}$ and $10^{4}$ year timescales: Insights into variability in the seismic cycle in the central Apennines, Italy, J. Geophys. Res., 115, B10418; doi:10.1029/2009JB006462.

Frepoli, A., and A. Amato (1997). Contemporaneous extension and compression in the northern Apennines from earthquake fault-plane solutions, Geophys. J. Int., 129, 268-388.

Galadini, F., and P. Messina (1994). Plio-Quaternary tectonic of the Fucino basin and surroundings areas (central Italy), Giorn. Geol., 56, 73-99.

Galadini, F., and P. Galli (2000). Active tectonics in the central Apennines (Italy) - input data for seismic hazard assessment, Nat. Hazard, 22, 225-270.

Herring, T., R.W. King and S. McClusky (2006). GAMIT Ref- erence Manual, Release 10.3. Department of Earth, Atmospheric, and Planetary Sciences, Massachussetts Institute of Technology; http://www-gpsg.mit.edu/ simon/gtgk/ .

Hunstad, I., G. Selvaggi, N. D'Agostino, P. England, P. Carke and M. Pierozzi (2003). Geodetic strain in peninsular Italyt between 1875 and 2001, J. Geophys. Res. Lett., 30 (4), 1181, doi:10.1029/2002GL016447.

Lundgren, P., E.A. Hetland, L. Zhen and E.J. Fielding (2009). Southern San Andreas-San Jacinto fault system slip rates estimated from earthquake cycle models constrained by GPS and interferometric synthetic aperture radar observation, J. Geophys. Res., 114, B02403; doi:10.1029/2008JB 005996.

Malinverno, A., and W.B.F. Ryan (1986). Extension in the Tyrrhenian Sea and shortening in the Apennines as result of arc migration driven by sinking of the lithosphere, Tectonics, 5, 227-245.

McCarthy, D.D., and G. Petit (2004). IERS Conventions (2003). IERS Technical Note 32, Verlag des Budesamts fur Kartographie und Geodasie, Frankfurt, paperback, ISBN 3-89888-884-3 (print version).

McClusky, S., S. Balassanian, A. Barka, C. Demir, S. Ergintav, I. Georgiev, O. Gurkan, M. Hamburger, K. Hurst, H. Kahle, K. Kastens, G. Kekelidze, R. King, V. Kotzev, O. Lenk, S. Mahmoud, A. Mishin, M. Nadariya, A. Ouzounis, D. Paradissis, Y. Peter, M. Prilepin, R. Reilinger, I. Sanli, H. Seeger, A. Tealeb, M.N. Toksöz and G. Veis (2000). Global positioning system constraints on plate kinematics and dynamics in the eastern Mediterranean and Caucasus, J. Geophys. Res., 105, 5695-5719.

Noquet, J.M., E. Calais, Z. Altamimi, P. Sillard and C. Boucher (2001). Intraplate deformation in western Europe deduced from analysis of the International Terrestrial Reference Frame 1997 (ITRF97) velocity field, J. Geophys. Res., 106, 11239-11257.

Patacca, E., R. Sartori and P. Scandone (1990). Tyrrhenian basin and Apenninic arcs; kinematic relations since Late Tortonian times, Mem. Soc. Geol. It., 45, 425-451.

Pesci, A., G. Teza, G. Casula, N. Cenni and F. Loddo (2010). Non-permanent GPS data for regional-scale kinematics: reliable deformation rate before the 6 April, 2009, earthquake in the L'Aquila area, Annals of Geophysics, 53 (2), 55-68; doi:10.4401/ag-4740.

Reutter, K.J., P. Gieseand and H. Closs (1980). Lithospheric split in the descending plate: observations from the northern Apennines, Tectonophysics, 64, T1-T9.

Royden, L., E. Patacca and P. Scandone (1987). Segmentation and configuration of subducted lithosphere in Italy: an important control on thrust-belt and foredeep-basin evolution, Geology, 15, 714-717.

Schaffrin, B., and Y. Bock (1988). A unified scheme for processing GPS phase observations, Bull. Geodesique, 62, $142-160$. 
Selvaggi, G. (1998). Spatial distribution of horizontal seismic strain in the Apennines from historical earthquakes, Annali di Geofisica, 41 (2), 241-251; doi:10.4401/ag-4334.

Selvaggi, G., et al. (2006). La "Rete Integrata Nazionale GPS" (RING) dell'INGV: una infrastruttura aperta per la ricerca scientifica, Atti $10^{\text {a }}$ Conferenza Nazionale ASITA, 17491754 (in Italian).

Serpelloni, E., M. Anzidei, P. Baldi, G. Casula and A. Galvani (2005). Crustal velocity and strain-rate fields in Italy and surrounding regions: new results from the analysis of permanent and non-permanent GPS networks, Geophys. J. Int., 161, 861-880; doi:10.1111/j.1365-246X.2005.02618.x. Serpelloni, E., G. Casula, A. Galvani, M. Anzidei and P. Baldi (2006). Data analysis of permanent GPS networks in Italy and surrounding regions: application of a distributed processing approach, Annals of Geophysics, 49 (4/5), 897928; doi:10.4401/ag-4410.

Shen, Z-K., D.D. Jackson and B.X. Ge (1996). Crustal deformation across and beyond the Los Angeles basin from geodetic measurements, J. Geophys. Res., 101, 27957-27980.

Shen, Z-K., D.D. Jackson and Y.Y. Kagan (2007). Implication of geodetic strain rate for future earthquakes, with a fiveyear forecast of M5 earthquakes in southern California, Seismol. Res. Lett., 78, 116-120.

Valensise, G., and D. Pantosti, eds. (2001). Database of potential sources for earthquakes larger than M 5.5 in Italy, Annali di Geofisica, Supplement to vol. 44 (4), 180 pp.

Vespe, F., G. Bianco, M. Fermi, C. Ferraro, A. Nardi and C. Sciarretta (2000). The Italian GPS fiducial network: services and products, J. Geodyn., 30, 327-336.

\footnotetext{
${ }^{\star}$ Corresponding author: Alessandro Galvani, Istituto Nazionale di Geofisica e Vulcanologia, Centro Nazionale Terremoti, Rome, Italy ; email: alessandro.galvani@ingv.it. 